\title{
Electrochemically Exfoliated Graphene for High-Durability Cement Composites
}

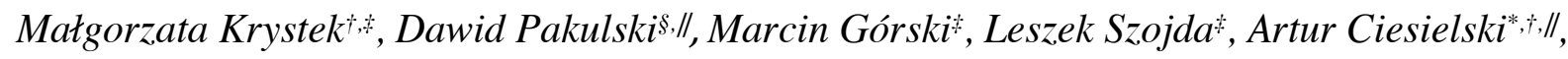 \\ Paolo Samori ${ }^{*}$,
}

† Université de Strasbourg, CNRS, ISIS, 8 alleé Gaspard Monge, 67000 Strasbourg, France \$ Silesian University of Technology, Department of Structural Engineering, Akademicka 5, 44100 Gliwice, Poland

$\S$ Faculty of Chemistry, Adam Mickiewicz University, Umultowska 89b, 61-614 Poznań, Poland ॥ Centre for Advanced Technologies, Adam Mickiewicz University, Umultowska 89c, 61-614 Poznań, Poland

KEYWORDS: chloride penetration, electrochemically exfoliated graphene, Portland cement, sulphate attack, water sorptivity 
ABSTRACT: The development of radically new types of corrosion resistant cement composites is nowadays compulsory in view of the continuous increase of concrete consumption combined with the intrinsically defective nature of concrete. Among various additives being employed in concrete technology, carbon nanomaterials have emerged as extremely powerful components capable to remarkably enhance nano- and micro-structure as well as properties of cement-based composites. In this study we demonstrate that cement mortar incorporating electrochemically exfoliated graphene (EEG) exhibits significantly improved fluid transport properties. The addition of $0.05 \mathrm{wt} . \%$ of EEG to ordinary Portland cement mortar results in the reduction of initial and secondary sorptivity by $21 \%$ and $25 \%$, respectively. This leads to the outstanding resistance of EEG-cement composites to highly corrosive environments, namely chloride and sulfate solutions. These observations, combined with the previously reported remarkable enhancement of the tensile strength of EEG-cement mortars, represent a major step forward towards the development of highly durable graphene-based cement composites. 
Since the development of Portland cement formula in $1824^{1}$ scientists have incessantly focused their efforts towards enhancing the durability of cementitious composites. ${ }^{2}$ Such grand-challenge is key because concrete structures are continuously exposed to the harsh weather conditions as well as aggressive and harmful agents., ${ }^{3,4}$ The durability of concrete is hampered by its highly porous microstructure allowing hazardous ions to penetrate into the cement skeleton. ${ }^{5}$ As a consequence, the corrosion of both concrete and steel reinforcement occurs extensively thereby devastating the building structures. This affects drastically the comfort and the safety of buildings' users. Therefore, the degraded concrete structures require complex and expensive reparations to avoid the construction failure. The economic aspects, combined with the fact that concrete consumption is still increasing exponentially worldwide on the yearly basis, ${ }^{6}$ make the enhancement of concrete performance when exposed to harmful environment one among the major tasks in civil engineering. Moreover, it is worth taking into account the environmental impact of concrete manufacturing, i.e., the high energy intensity ${ }^{7,8}$ and $\mathrm{CO}_{2}$ emission ${ }^{8}$ during cement production as well as notable water consumption. ${ }^{9}$ Concrete members require to be designed using materials and protocols ensuring improved durability over the years, not only to minimize the need of interventions and associated maintenance costs,${ }^{10}$ but also to reduce the negative environmental effects associated to concrete production. Therefore, radically new types of highly durable cementitious composites with unconventional composition allowing to mitigate concrete corrosion are sought-after in today's building industry.

The development of cement nanocomposites, i.e., cement composites incorporating various nanomaterials, represented a real breakthrough in concrete technology. ${ }^{11,12}$ Among them, graphene derivatives emerged as the most attractive components. However, although numerous researchers have already revealed the beneficial influence of graphene and derivatives thereof on the 
mechanical properties, microstructure and the porosity of cementitious composites, ${ }^{13,14}$ similar studies involving the durability-related properties remain limited. Up to date, the potential effect of graphene oxide (GO) and graphene nanoplatelets (GNPs) on the sorptivity, 5,15-21 carbonation, ${ }^{19,20,22}$ chloride $^{5,16,21,23-25}$ and sulphate ${ }^{23}$ corrosion as well as freeze-thaw resistance ${ }^{19,20}$ of cement composites has been somewhat evaluated. Most importantly, it has been reported that the addition of GO notably reduces the sorptivity of cement composites..$^{15-20}$ The maximum reduction of $46 \%{ }^{18}$ and $44 \%{ }^{15}$ has been quantified for initial and secondary sorptivity, respectively, if compared to plain composites. The authors attributed this phenomenon to the results of the porosity measurements, i.e., to the significant refinement of large capillary pores. ${ }^{16}$ As a consequence, the decreased mobility of chloride and sulfate ions within cement matrix ${ }^{16,23}$ as well as the improved performance of cement composites during freeze-thaw cycles ${ }^{19,20}$ and carbonation tests ${ }^{19,20,22}$ have been reported in several studies. Similarly, comparable results have been obtained for GNP-cement composites revealing a significantly reduced water penetration depth, even by $75 \%,{ }^{5,21}$ accompanied by an increased chloride migration resistance..$^{5,21,24,25}$ Such works provided evidence for the great potential of GO and GNPs in improving the durability of cementitious composites by mitigating the penetration of harmful ions within cement matrix (Figure 1). However, it should be emphasized that the technological transfer of such composites toward largescale applications remains challenging because of the difficulty in obtaining a uniform dispersion of the nanomaterials within cement matrix. On the one hand, the incorporation of GO into cement paste leads to the chemical cross-linking of GO nanosheets by calcium ions, thus resulting in their immediate flocculation. ${ }^{26} \mathrm{GO}$ agglomerates entrap free water molecules thus negatively affecting the workability of cement composites and deteriorating the GO dispersion within cement matrix. On the other hand, GNPs also proved to agglomerate in cement environment due to their 
hydrophobic nature. ${ }^{27}$ In general, major limitation of graphene-cement composites reported so far in the literature arises from the chosen manufacturing procedures which are not applicable on an industrial scale. Clearly, such method as the sonication of GO or GNPs with different types of surfactants and water prior to adding cement ${ }^{5,17-19,21,23-25}$ precludes the viable implementation of cement nanocomposites. Moreover, Jing et al. ${ }^{28}$ have recently revealed the limited dispersion ability of the most commonly used polycarboxylate superplasticizers. The 3D visualization of the GO-cement specimens obtained via micro computed tomography (micro-CT) has revealed irregular GO agglomerates confirming that the microstructure and mechanical properties of cementitious composites incorporating GO are highly dependent on the degree of GO dispersion and applied dispersion technique. 
a)

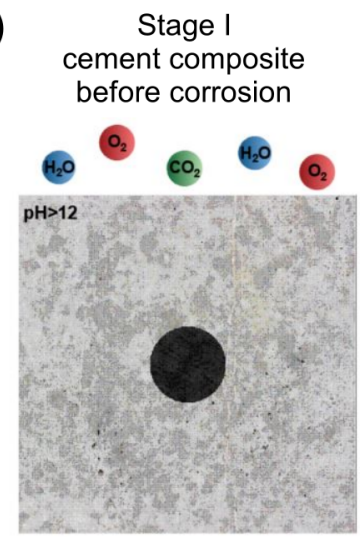

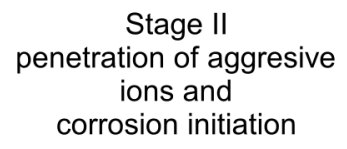

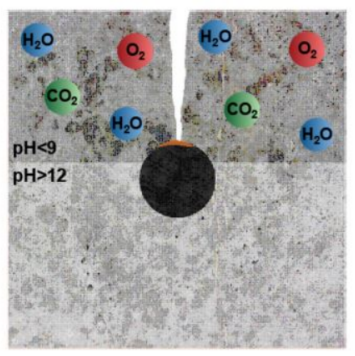

b)

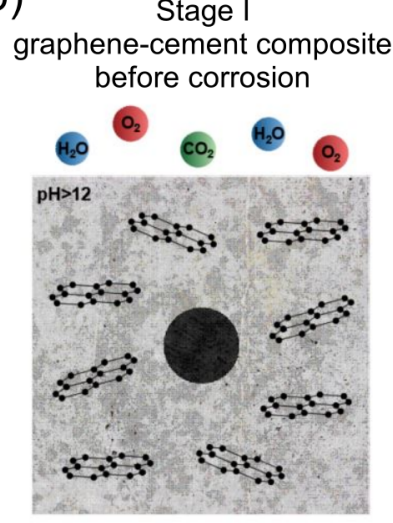

Stage III

further corrosion and propagation of cracks

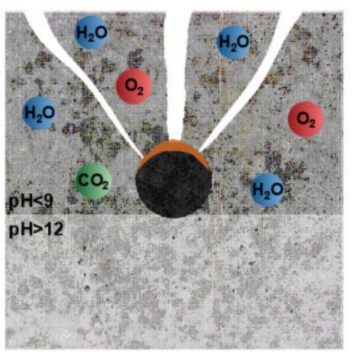

Stage II inhibited penetration of aggresive ions

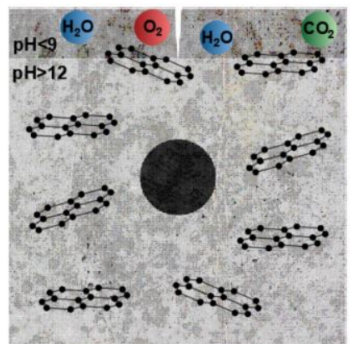

Stage IV

spalling and further degradation of composite

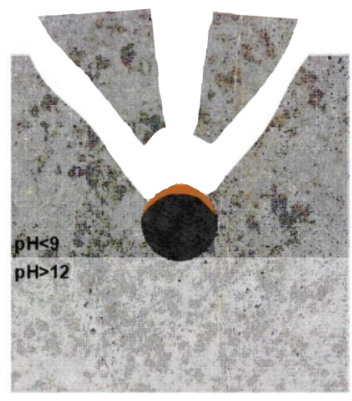

Figure 1. The stages of a) the degradation of plain concrete when exposed to aggressive environment, and b) the effect of graphene incorporation on concrete corrosion.

Noteworthy, we have recently reported on properties of cement mortars incorporating electrochemically exfoliated graphene (EEG). ${ }^{29,30}$ Significantly, our novel functional composite featured a tremendously increased tensile strength, by $79 \%$, as well as markedly refined microstructure with higher formation of C-S-H phase and decreased amount of portlandite. In this regard, our EEG-cement composite outperforms recently reported composites with electrochemically exfoliated graphene. In particular, Ho et al..$^{11,32}$ have revealed cement mortars incorporating the industrially manufactured pristine graphene obtained by the electrochemical process. It should be emphasized that graphene used within this study was a ultra-large particle 
size graphene with the in-plane size of $5 \mu \mathrm{m}, 43 \mu \mathrm{m}, 56 \mu \mathrm{m}$ and $73 \mu \mathrm{m}$. The particle size of $73 \mu \mathrm{m}$ has resulted in the highest increase of the tensile strength of $33.5 \%$ and $38.6 \%$ for samples cured for 7 and 28 days, respectively. Noteworthy, the addition of pristine graphene has led to the reduction of flowability of processed composites by $22.7 \%$, even with the surfactant used. Importantly, we have devised a simple and efficient method for preparing cement composites incorporating electrochemically exfoliated graphene..$^{29,30}$ The manufacturing procedure does not require the use of surfactants or any special treatment to obtain the uniform dispersion of graphene within cement matrix or to ensure the appropriate workability of fresh mix. Significantly, our novel functional composite featured a tremendously increased tensile strength, by $79 \%$, as well as markedly refined microstructure with higher formation of C-S-H phase and decreased amount of portlandite. Moreover, the extensive comparison of EEG-cement composites with their counterparts incorporating $\mathrm{GO}^{29,30}$ has revealed that even low quantities of calcium ions may lead to the immediate formation of GO agglomerates within cement matrix. Therefore, due to the poor workability and thus insufficient compaction of fresh cement mortar, the hydration and microstructure of GO-cement composites was significantly hindered, thus leading to the deteriorated mechanical properties. These results, as an indication of significantly inhibited transport of liquids within EEG-cement mortars significantly outperforming GO-based cement composites, prompted us to investigate further the durability of the produced composites.

Here we show the effect of a few-layer thick electrochemically exfoliated graphene on the resistance of cement composites when exposed to corrosive environments. In an effort to explore the effect of porosity of cement mortars, we first investigated their initial and secondary sorptivity. The most beneficial graphene loading, i.e., $0.05 \mathrm{wt} . \%$ by weight of cement, was found to exhibit a decrease of the initial and secondary sorptivity by $21 \%$ and $25 \%$, respectively, due to the 
refinement of capillary pores and the high formation of $\mathrm{C}-\mathrm{S}-\mathrm{H}$ phase. Then we evaluated the influence of sulfate environment on the compressive strength of EEG-cement mortars. While sulfate ions contributed to the degradation of reference mortar as well as to the deterioration of its compressive strength, their effect on both appearance as well as mechanical properties of EEGbased composites was negligible. Finally, we opted to determine the effect of EEG on the mobility of chloride ions within cement composites. We found experimentally that $0.05 \mathrm{wt} . \%$ addition of EEG results in the significantly reduced chloride penetration depth, i.e., by $50 \%$. Moreover, the chloride content measured in samples incorporating $0.05 \mathrm{wt} . \%$ of EEG turned out to be diminished by $32 \%-40 \%$, if compared with plain cement mortar. Above all, our studies provide unambiguous evidence that our hybrid composites hold great potential for the industrial-scale application of graphene in highly durable concrete structures.

\section{RESULTS AND DISCUSSION}

Water sorptivity. Since the durability of cementitious composites is highly affected by their fluid transport properties, we first investigated the sorptivity of all produced mortars. In this regard, the determination of sorptivity, defined as the rate of capillary-rise absorption of water, is a widely employed method providing direct insight into the porosity of cement composites. ${ }^{1}$ Onedimensional sorptivity coefficient is determined as the slope of the linear regression of cumulative water absorption against the square root of time. The cumulative water absorption at time t may be expressed as an increase of water level in cementitious sample: ${ }^{15,16}$

$l_{t}=\frac{\Delta m_{t}}{A \times d_{w}}[\mathrm{~mm}]$ 
where $\Delta m_{t}$ is the sample mass change after time $t, A$ represents the cross-section area exposed to water and $d_{w}$ represents the water density.

Interestingly, the water absorption process comprises two main phases highly visible on the cumulative water absorption plot: initial and secondary sorptivity. Typically, the initial sorptivity is the slope of the curve during first $6 \mathrm{~h}$, while the secondary sorptivity is defined between 1 and 7 days. ${ }^{15,16}$ However, to obtain the relevant values of sorptivity, the correlation coefficient of leastsquare linear regression should exceed 0.98 . As a consequence, this recommendation did not allow us to fit the linear regression to the results obtained between 1 and 7 days (see Figure $\mathrm{S} 1$ in Supporting Information). Therefore, we have opted to determine the secondary sorptivity as the sorptivity between 3 and 7 days (Figure $2 a)$.

a)

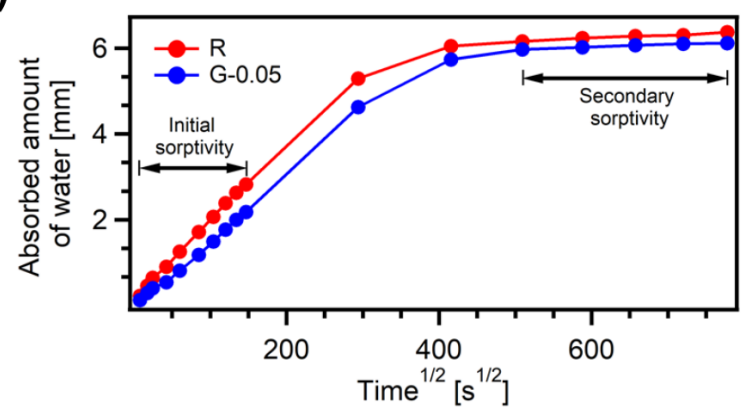

c)

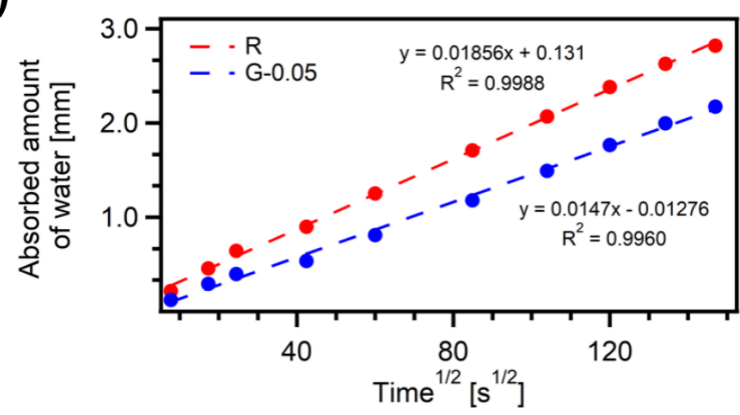

b)

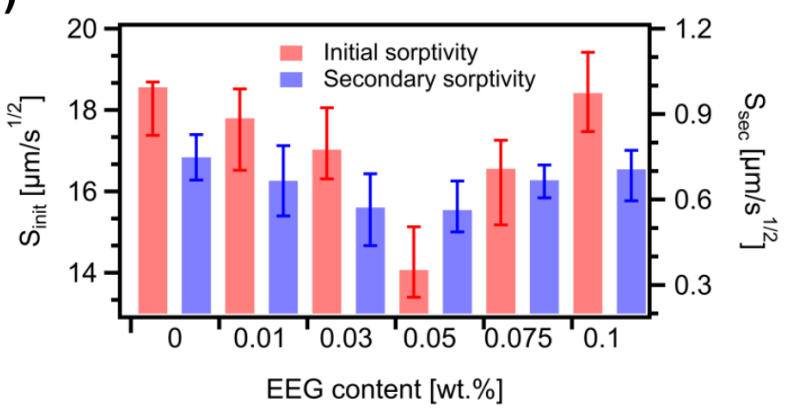

d)

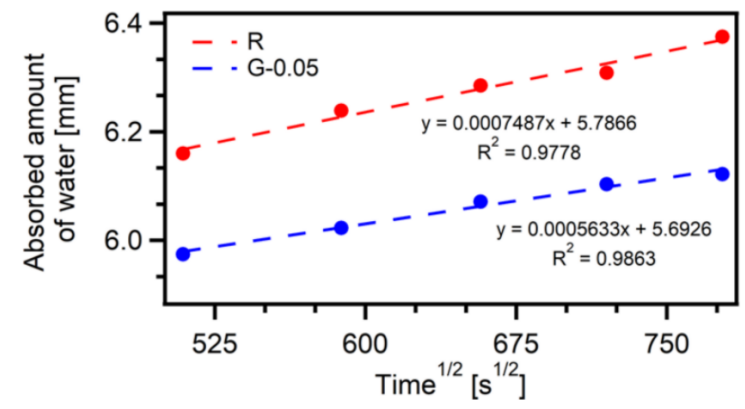

Figure 2. Water sorption measurements: (a) The amount of water absorbed from 1 min to 7 days for R and G-0.05 samples with the initial and secondary sorptivity ranges. (b) The initial and secondary sorptivity for all cement mortars. (c) and (d) The absorbed water amount in R and G- 
0.05 samples with the linear regression for the (c) initial and (d) secondary sorptivity determination.

Noteworthy, the sorptivity of cement mortars is notably reduced with the introduction of a fewlayer graphene, achieving the lowest values for G-0.05 samples (Figure 2b). We observed that samples with $0.05 \mathrm{wt} . \%$ loading of EEG exhibit the significant reduction of initial and secondary sorptivity by $21 \%$ (from $18.56 \mu \mathrm{m} / \mathrm{s}^{1 / 2}$ to $14.7 \mu \mathrm{m} / \mathrm{s}^{1 / 2}$ ) and $25 \%$ (from $0.7487 \mu \mathrm{m} / \mathrm{s}^{1 / 2}$ to 0.5633 $\mu \mathrm{m} / \mathrm{s}^{1 / 2}$ ), respectively (Figure $2 \mathrm{c}, \mathrm{d}$ ). However, even the lowest graphene content, i.e., $0.01 \mathrm{wt} . \%$, contributes visibly to the decrease of sorptivity of tested composites, in particular the secondary sorptivity (Figure S2a,c). With an EEG loading higher than 0.05 wt.\%, the sorptivity coefficients approach the values obtained for reference specimens (Figure S2b,d). Nevertheless, in case of secondary sorptivity, even the highest dosage of graphene results in the sorptivity coefficient decreased by $6 \%$.

Importantly, it should be emphasized that there is a clear correlation between the results of sorption measurements and our previous observations..$^{29,30}$ The 0.05 wt.\% loading of EEG has already proved to be the most beneficial considering both the mechanical and microstructural characterization of cement composites. In particular, our studies revealed an increased content of C-S-H gel, and the higher degree of cement hydration in samples with graphene when compared with plain cement mortar. Indeed, the enhanced sorptivity is a fingerprint of the tremendously refined microstructure of cement-graphene composites with the high formation of gel pores. On the one hand, the initial sorptivity, up to $6 \mathrm{~h}$, is attributed to the presence of large capillary pores within cement matrix, ${ }^{16}$ therefore the remarkable reduction of the initial sorptivity in samples with $0.05 \mathrm{wt} . \%$ graphene loading indicates that the amount of capillary pores up to $100 \mathrm{~nm}$ in size is significantly limited in as produced composite. This observation is in line with previously reported 
SEM images of G-0.05 composites ${ }^{29,30}$ showing regular and densified microstructure with the lack of large pores. On the other hand, the secondary sorptivity, after a few days of immersion in water, is strongly influenced by the gel porosity (pores up to $2 \mathrm{~nm}$ in diameter) of C-S-H phase impairing the continuity of the capillary pores and thus the mobility of fluids. ${ }^{18}$ By and large, the observed decreased secondary sorptivity in composites incorporating EEG is caused primarily by the regular highly hydrated microstructure composed of C-S-H phase full of small gel pores up to $2 \mathrm{~nm}$. However, it should be highlighted that a slight reduction of secondary sorptivity was observed also in G-0.1 mortar, which emerged previously as a composite with properties and microstructure comparable to those reported for reference samples. ${ }^{29,30}$ This observation can be explained by the fact that, with the higher loading of EEG, graphene flakes start to act as an extensive barrier increasing the tortuosity of the paths for water penetration.

Sulfate attack. We then extended our studies to the evaluation of sulfate corrosion resistance of all cement mortars incorporating EEG. The corrosion of concrete caused by sulfate ions, which originates mostly from seawater or groundwater, is a typical example of a corrosion involving expansive reactions occurring within cement matrix. The expansive reactions lead to the formation of low soluble compounds, mainly gypsum $\left(\mathrm{CaSO}_{4} \cdot 2 \mathrm{H}_{2} \mathrm{O}\right)$ and ettringite $\left(\mathrm{Ca}_{6} \mathrm{Al}_{2}(\mathrm{OH})_{12}\left(\mathrm{SO}_{4}\right)_{3} \cdot 26 \mathrm{H}_{2} \mathrm{O}\right)$, inducing the crystallization pressure and thus resulting in cracking and degradation of concrete. ${ }^{1,33}$

Sodium sulfate, being one of the most common and, simultaneously, one of the most corrosive salts for cementitious composites, extensively reacts with both major hydration products, i.e., the $\mathrm{Ca}(\mathrm{OH})_{2}$ and C-S-H phase. ${ }^{1,33}$ Initially, sodium sulfate reacts with calcium hydroxide; as a result, gypsum is formed: 
$\mathrm{Na}_{2} \mathrm{SO}_{4}+\mathrm{Ca}(\mathrm{OH})_{2}+2 \mathrm{H}_{2} \mathrm{O} \rightarrow 2 \mathrm{NaOH}+\mathrm{CaSO}_{4} \times 2 \mathrm{H}_{2} \mathrm{O}$

While the concentration of calcium and sulfate ions in liquid phase exceeds gypsum solubility equilibrium, the crystallization of gypsum will occur. Unfavorably, further reactions of calcium and sulfate ions will result in the formation of ettringite:

$$
\begin{gathered}
2 \mathrm{Ca}^{2+}+2 \mathrm{SO}_{4}^{2-}+\mathrm{Ca}_{4} \mathrm{Al}_{2}(\mathrm{OH})_{12} \mathrm{SO}_{4} \times 6 \mathrm{H}_{2} \mathrm{O}+20 \mathrm{H}_{2} \mathrm{O} \rightarrow \\
\mathrm{Ca}_{6} \mathrm{Al}_{2}(\mathrm{OH})_{12}\left(\mathrm{SO}_{4}\right)_{3} \times 26 \mathrm{H}_{2} \mathrm{O} \\
2 \mathrm{Ca}^{2+}+3 \mathrm{SO}_{4}^{2-}+\mathrm{Ca}_{4} \mathrm{Al}_{2}(\mathrm{OH})_{12} \times 6 \mathrm{H}_{2} \mathrm{O}+20 \mathrm{H}_{2} \mathrm{O} \rightarrow \mathrm{Ca}_{6} \mathrm{Al}_{2}(\mathrm{OH})_{12}\left(\mathrm{SO}_{4}\right)_{3} \times 26 \mathrm{H}_{2} \mathrm{O}
\end{gathered}
$$

On the one hand, both products, gypsum and ettringite, are strongly expansive compounds drastically devastating the microstructure of cement composites (Figure 3a). On the other hand, it was demonstrated ${ }^{33}$ that sodium sulfate contributes also to the slow decalcination of C-S-H phase, thus additionally decreasing the strength of cement paste:

$$
\begin{gathered}
1.75 \mathrm{CaOSiO}_{2} \times n \mathrm{H}_{2} \mathrm{O}+x \mathrm{Na}_{2} \mathrm{SO}_{4}+2 x \mathrm{H}_{2} \mathrm{O} \rightarrow \\
(1.75-x) \mathrm{CaOSiO}_{2}-n \mathrm{H}_{2} \mathrm{O}+2 x \mathrm{NaOH}+x \mathrm{CaSO}_{4} \times 2 \mathrm{H}_{2} \mathrm{O}
\end{gathered}
$$




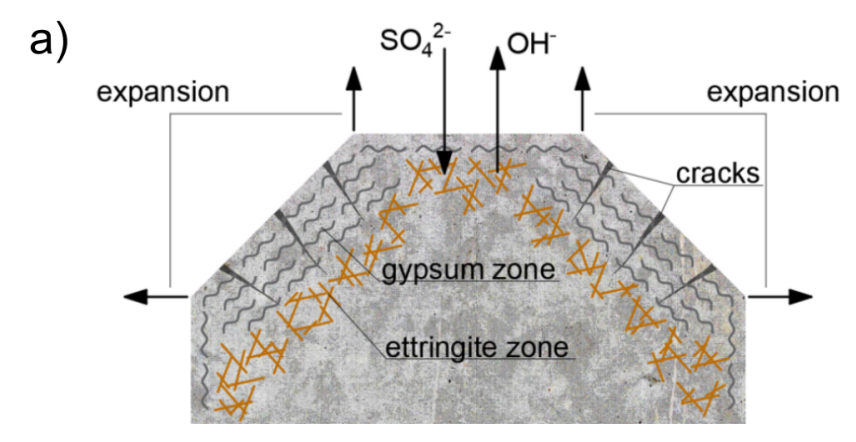

b)

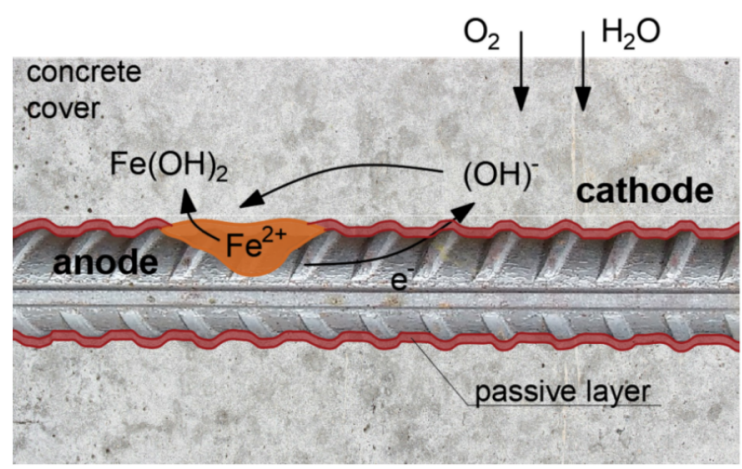

c)

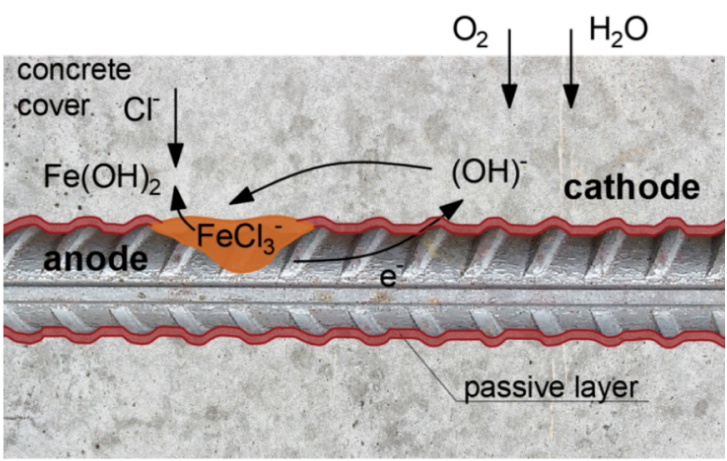

Figure 3. Most common corrosion processes affecting concrete durability: (a) The course of sulfate-induced corrosion of cementitious composites. (b) and (c) The corrosion process of steel reinforcement in cementitious composites (b) without and (c) with the influence of chloride ions.

Moreover, $\mathrm{Na}_{2} \mathrm{SO}_{4}$ proved to foster the transformation of C-S-H phase into thaumasite, i.e., a calcium silicate mineral with the abbreviated chemical formula $\mathrm{CaCO}_{3} \cdot \mathrm{CaSO}_{4} \cdot \mathrm{CaSiO}_{3} \cdot 15 \mathrm{H}_{2} \mathrm{O}$. 34,35 The key factor in the formation of thaumasite during sulfate attack is the presence of dissolved atmospheric $\mathrm{CO}_{2}$ or $\mathrm{CO}_{3}{ }^{2-}$ ions originating from dissolved salts and carbonate aggregates: ${ }^{33,34}$

$$
\begin{aligned}
& 3 \mathrm{CaO} \times 2 \mathrm{SiO}_{2} \times 3 \mathrm{H}_{2} \mathrm{O}+2\left\{\mathrm{CaSO}_{4} \times 2 \mathrm{H}_{2} \mathrm{O}\right\} \\
& \rightarrow 2 \mathrm{CaCO}_{3}\left[\mathrm{Si}(\mathrm{OH})_{6}\right]\left(\mathrm{CO}_{3}\right)\left(\mathrm{CO}_{4}\right) \times 12 \mathrm{H}_{2} \mathrm{O}
\end{aligned}
$$

Originally, thaumasite was believed to be formed only at low temperatures $\left(<5^{\circ} \mathrm{C}\right),{ }^{33}$ however, recent studies have demonstrated that sulfate attack may contribute to the thaumasite formation 
also at higher temperatures, ${ }^{35}$ even in warm climates, ${ }^{34}$ leading to the softening of $\mathrm{C}-\mathrm{S}-\mathrm{H}$ phase and thus significantly decreasing the concrete strength.

Therefore, considering the aforementioned mechanisms of sulfate corrosion, we studied the influence of a few-layer graphene on the performance of cementitious composites in sulfate environment by means of visual assessment, compressive strength tests (Figure 4a), TGA and SEM. Towards this end, one series of EEG-cement mortars was stored in $\mathrm{Na}_{2} \mathrm{SO}_{4}$ solution for 56 days, while a second series was further cured in water.

a)

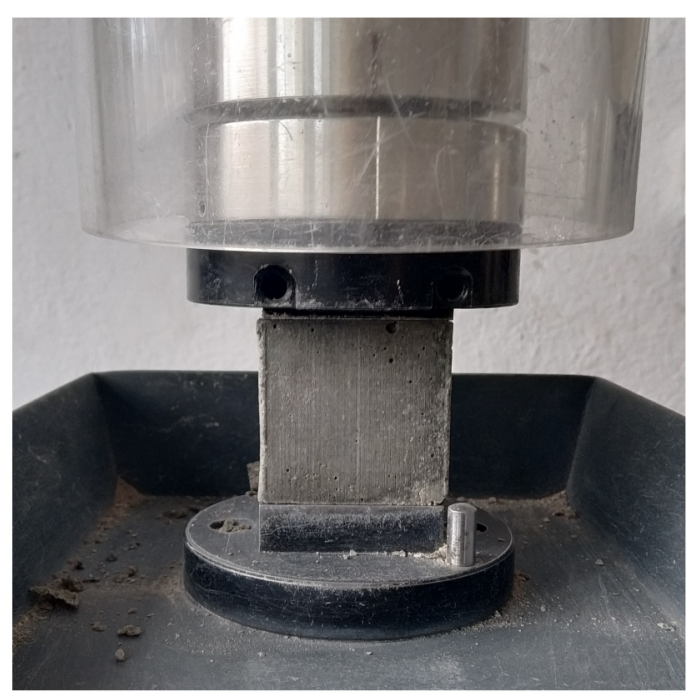

b)

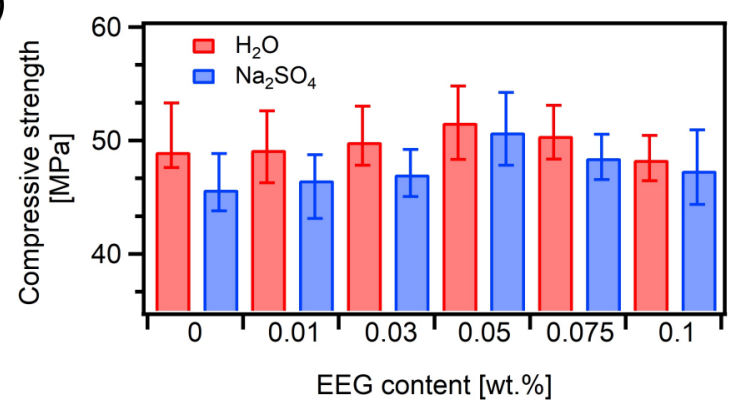

c)

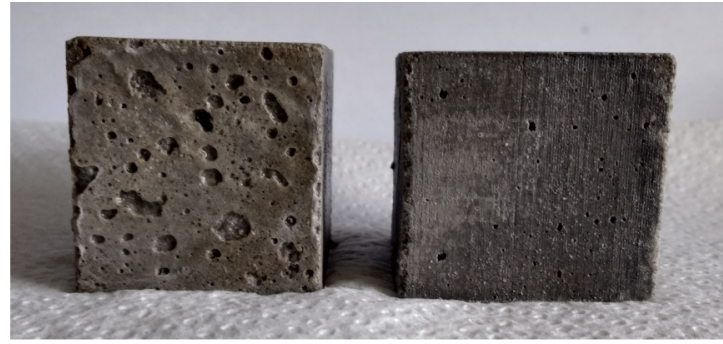

d)

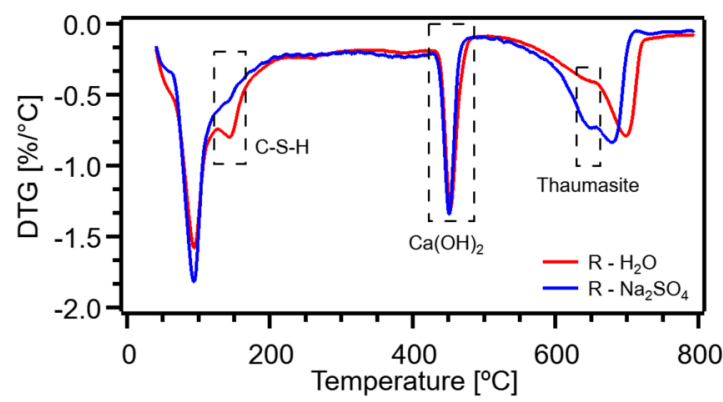

e)

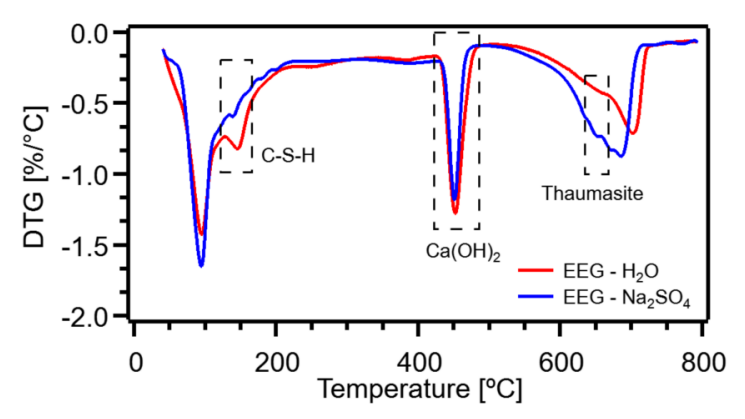


Figure 4. The evaluation of EEG-cement composites in sulfate environment: (a) The compressive strength test of cement mortar sample with the dimensions of $40 \times 40 \times 40 \mathrm{~mm}^{3}$. (b) The results of compression tests of all cement mortars stored in water or $\mathrm{Na}_{2} \mathrm{SO}_{4}$ solution for 56 days. (c) $\mathrm{R}$ (left) and G-0.05 (right) samples after 56 days of immersion in $\mathrm{Na}_{2} \mathrm{SO}_{4}$ solution. (d) and (e) TGA curves of (d) $\mathrm{R}$ and (e) G-0.05 samples stored in water and $\mathrm{Na}_{2} \mathrm{SO}_{4}$ solution.

Significantly, visual assessment of samples removed from $\mathrm{Na}_{2} \mathrm{SO}_{4}$ solution revealed the highly visible degradation of the surface of reference samples (Figure 4c), the indication of ongoing expansive reactions. Conversely, the surface of G-0.05 composite stored in sodium sulfate solution appeared unaltered compared to specimens cured in non-corrosive environment. Importantly, our observations are further confirmed by the results of compressive strength tests plotted in Figure 4b. In case of plain cement mortar, sulfate ions contributed to the reduction of compressive strength by ca. $6.8 \%$, while the effect of sulfate environment turned out to be negligible in samples incorporating $0.05 \mathrm{wt} . \%$ loading of graphene, since the reduction of the compressive strength of G-0.05 samples was as low as $1.7 \%$, due to a minor decrease from 51.6 MPa to 50.7 $\mathrm{MPa}$. In particular, the high durability of EEG-cement mortars during sulfate-induced corrosion is caused by the significantly reduced sorptivity of the composites. However, the strength weakening of mortars with higher dosages of graphene, i.e., $0.075 \mathrm{wt} . \%$ and $0.1 \mathrm{wt} . \%$, can be also considered as marginal, thus suggesting that sulfate ions may be stacked between numerous graphene sheets and their reactions with hydration products are therefore inhibited.

In order to cast further light onto the effect of EEG on the formation of expansive compounds under sulfate attack, we extended our studies to TGA measurements of plain cement composites and composites containing $0.05 \mathrm{wt} . \%$ of EEG. Indeed, TGA proved to be a powerful technique for 
evaluating the hydration degree of cement composites and differentiating the hydration products. Fundamentally, four highly visible characteristic peaks can be seen in the thermogravimetric derivative (DTG) curve of plain cement mortar (Figure 4d). The proper identification of the first peak appearing at $105^{\circ} \mathrm{C}$ remains extremely challenging due to the superposition of various phenomena: on the one hand, some authors attributed the weight loss in this region to the decomposition of C-S-H phase ${ }^{36,37}$ or ettringite, ${ }^{38}$ on the other hand, it should be pointed out that heating cement specimens up to $105^{\circ} \mathrm{C}$ removes mostly evaporable water ${ }^{38,39}$ and thus the peak size strongly depends on the sample moisture. As widely known, ${ }^{40,41}$ further peaks at $140^{\circ} \mathrm{C}$, between $420-500^{\circ} \mathrm{C}$ and $600-750^{\circ} \mathrm{C}$ can be ascribed, to a great extent, to the decomposition of amorphous C-S-H gel, the dehydroxylation region of $\mathrm{Ca}(\mathrm{OH})_{2}$ and the decarbonation region of $\mathrm{CaCO}_{3}$, respectively.

Quite surprisingly, no significant reduction of $\mathrm{Ca}(\mathrm{OH})_{2}$ content was observed in composites exposed to sulfate attack, indicating the restraint formation of expansive compounds, i.e., ettringite and gypsum (Figure 4d,e). Nevertheless, the comparison of DTG curves obtained for samples stored in water and $\mathrm{Na}_{2} \mathrm{SO}_{4}$ solution clearly reveals the reduction of C-S-H peak at $140^{\circ} \mathrm{C}$ as a result of sulfate environment. Interestingly, the notable change of the TGA plots in the decarbonation region is evidenced for samples cured in $\mathrm{Na}_{2} \mathrm{SO}_{4}$, i.e., the appearance of the new peak at $650^{\circ} \mathrm{C}$ representing thaumasite decarbonation. ${ }^{34,35}$ In fact, these results above taken together indicate that the microstructure and mechanical properties of cement mortar were deteriorated not by the formation of expansive compounds, but rather by the transformation of CS-H phase into weak and soft thaumasite. Here, as in the case of mechanical properties, cementEEG mortar demonstrated higher resistance to sulfate attack: TGA plot reveals a lower reduction of C-S-H amount as well as less clear thaumasite peak, if compared with reference mortar. 
Noteworthy, these observations are further supported with SEM images (Figure 5 and S3) of specimens stored in water as well as in $\mathrm{Na}_{2} \mathrm{SO}_{4}$ solution. Primarily, SEM images of samples exposed to non-corrosive aqueous environment confirmed the beneficial effect of EEG on the microstructure of cement composites..$^{29,30}$ While a plethora of weak hydration compounds, such as ettringite and portlandite, was easily detected in plain cement mortar (Figure 5a), EEG mortar visibly features with regular and compact microstructure composed mainly of C-S-H gel (Figure 5b). SEM images of mortar exposed to sulfate attack were collected for the external surface of dried pieces of the samples as well as for the fracture surface after additional splitting of the pieces. The former revealed agglomerates of thin needle-like crystals of thaumasite and, quite interestingly, high amount of thernadite crystals, i.e., anhydrous sodium sulfate mineral ${ }^{42}$ attached to the surface of specimens in evaporation zone (Figure $5 \mathrm{c}, \mathrm{d}$ ). Nevertheless, it should be highlighted that the agglomerations of both thaumasite and thenardite are more highly noticeable in reference samples than in EEG ones. The latter SEM images showed a slightly impaired microstructure with thaumasite crystals. Noteworthy, even though the portlandite content remained relatively unaltered in samples stored in $\mathrm{Na}_{2} \mathrm{SO}_{4}$ compared to mortars cured in water, some gypsum crystals were clearly observed in plain mortar after sulfate attack (Figure 5e), while they were not detected in graphene-based composites (Figure 5f). 
a)

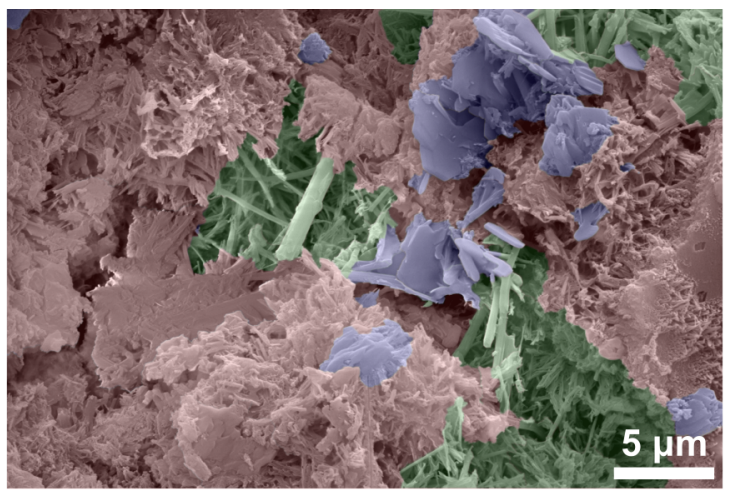

c)

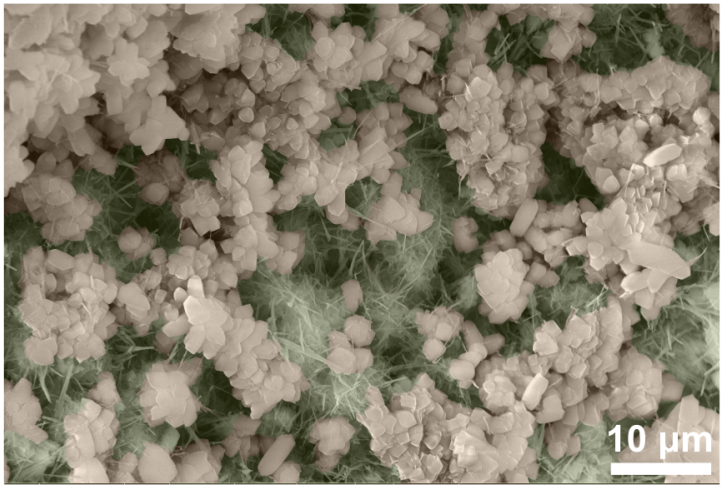

e)

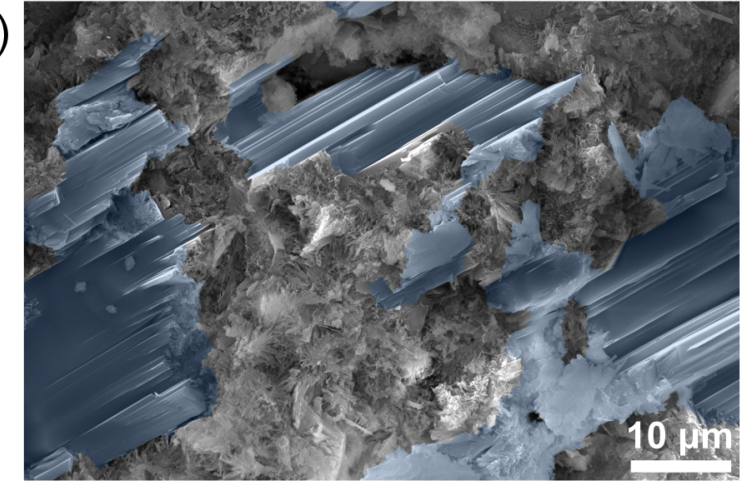

b)

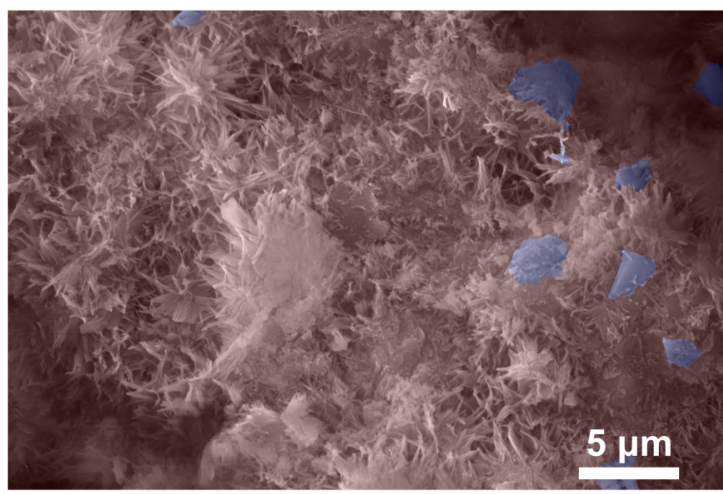

d)

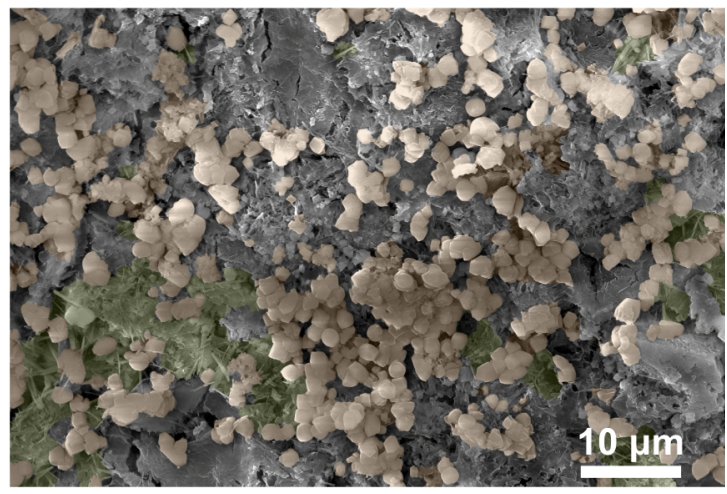

f)

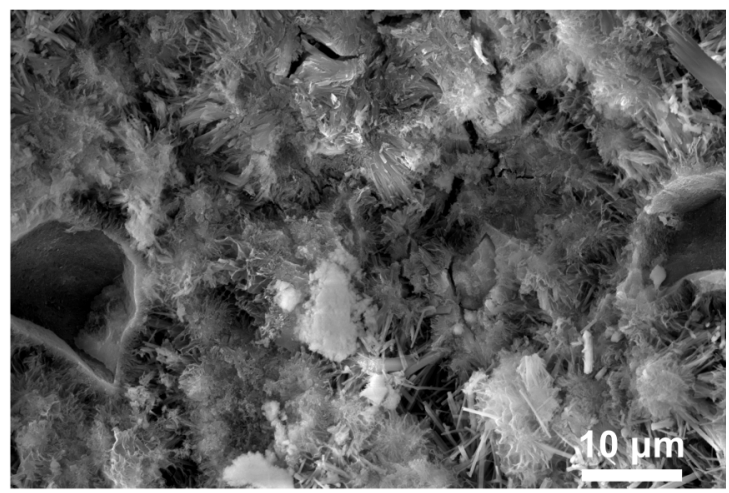

Figure 5. SEM images for: (a) R and (b) G-0.05 samples stored in water (red, green and violet colors represent C-S-H phase, ettringite and calcium hydroxide crystals, respectively), (c) and (d) the external surface of (c) R and (d) G-0.05 samples exposed to sulfate attack (light green and cream colors represent thaumasite and thenardite crystals, respectively), (e) and (f) the fracture surface of (e) R and (f) G-0.05 samples exposed to sulfate attack (blue color represents gypsum). Raw SEM images have been shown in Supporting Information. 
Chloride penetration. In order to cast further light onto the durability of cement-EGG composites, we have then focused our attention to the performance of as produced cement mortars in chloride environment. The corrosion induced by chloride ions coming from de-icing salts is widely considered being one of the most detrimental corrosion types affecting concrete durability.,33 This is most probably due to two reasons: the high mobility of chloride ions resulting in rapid concrete corrosion and their vast acidic aggressiveness in relation to highly alkaline cement composites. Typically, the chloride-induced corrosion is associated mostly with the corrosion of steel reinforcement. Nevertheless, it should be emphasized that cement matrix is the first component of hardened concrete that starts to deteriorate in chloride environment. Indeed, three main mechanisms of cement matrix deterioration can be distinguished: (1) osmotic pressure, (2) acidic corrosion with the dissolution of $\mathrm{Ca}(\mathrm{OH})_{2}$ and calcium leaching as well as (3) the formation of expansive compounds, namely calcium and magnesium chlorides. The migration of acidic chloride ions alters the cement paste thermodynamic balance and decreases the $\mathrm{pH}$ value thus contributing to the release of $\mathrm{OH}^{-}$ions by dissolving cement hydrates. The least durable compound in hardened cement paste, i.e., calcium hydroxide, starts to dissolve and that leads to the decalcination of C-S-H phase, which transforms into hydrated silica gel, thus losing strength and durability. ${ }^{1,31}$

Moreover, the strongly detrimental effect of chloride ions on concrete structures is also amplified by the simultaneous process of steel corrosion. ${ }^{1,33}$ Typically, the high alkalinity of cementitious composites ensures the formation of a passive protective layer composed of $\gamma-\mathrm{Fe}_{2} \mathrm{O}_{3}$ and $\mathrm{Fe}_{3} \mathrm{O}_{4}$ on the surface of steel reinforcement. However, chloride environment and thus reduced $\mathrm{pH}$ value of pore solution results in the depassivation and local puncture of the oxide layer, being the starting point for the anodic reaction: 
Simultaneously, the cathodic reaction proceeds on the reinforcement surface:

$2 \mathrm{H}_{2} \mathrm{O}+\mathrm{O}_{2}+4 e^{-} \rightarrow 4 \mathrm{OH}^{-}$

Therefore, since steel reinforcement acts as a metallic conductor and pore solution is an electrolytic environment providing the transport of ions, the local corrosive cell is created (Figure $3 b)$ :

$\mathrm{Fe}^{2+}+2 \mathrm{OH}^{-} \rightarrow \mathrm{Fe}(\mathrm{OH})_{2}$

Further reactions lead to the formation of rust as a mixture of following phases: $\mathrm{Fe}(\mathrm{OH})_{3}, \mathrm{Fe}_{2} \mathrm{O}_{3}$, $\mathrm{Fe}_{2} \mathrm{O}_{3} \cdot \mathrm{H}_{2} \mathrm{O}$. Basically, chloride ions act as inhibitors of steel corrosion in cement matrix by decreasing the anodic polarization and increasing the conductivity of cement paste. Even low concentration of chloride ions can modify the morphology of a passive layer leading to the formation of $\mathrm{FeCl}_{3}{ }^{-}$complex, reacting further with $\mathrm{OH}^{-}$ions (Figure $3 \mathrm{c}$ ): $:^{1,33}$

$\mathrm{Fe}+3 \mathrm{Cl}^{-} \rightarrow \mathrm{FeCl}_{3}^{-}+2 e^{-}$

$\mathrm{FeCl}_{3}^{-}+2 \mathrm{OH}^{-} \rightarrow \mathrm{Fe}(\mathrm{OH})_{2}+3 \mathrm{Cl}^{-}$

Noteworthy, the corrosion of steel reinforcement starts with the chloride ions content exceeding $0.5 \mathrm{wt} . \%$ by weight of cement and its rate is proportional to the increase of the chloride ions concentration up to $2 \mathrm{wt} . \% .^{33}$ Therefore, we have opted to investigate the effect of EEG addition 
on the migration of chloride ions within cement mortar. We first compared the chloride penetration depth in all prepared cement mortars after 21 days of immersion in $3 \mathrm{M} \mathrm{NaCl}$ solution. Towards this end, the fracture surface of specimens was sprayed with $\mathrm{AgNO}_{3}$ solution to reveal the chloride front as silvery-white precipitation of $\mathrm{AgCl}$ :

$\mathrm{AgNO}_{3}+\mathrm{Cl}^{-} \rightarrow \mathrm{AgCl} \downarrow+\mathrm{NO}_{3}^{-}$

The beneficial influence of a few-layer graphene on the chloride migration in cement mortars is clearly visible in Figure 6a,b. The most beneficial EEG loading, i.e., 0.05 wt.\%, proved to remarkably inhibit the mobility of chloride ions within cement matrix decreasing the chloride penetration depth by $50 \%$, from $8 \mathrm{~mm}$ to $4 \mathrm{~mm}$.

Furthermore, we evaluated the exact chloride content in all samples after 7, 14 and 21 days of $\mathrm{NaCl}$ storage by means of back titrimetric Volhard method:

$J_{C l}=\frac{10 *\left(V_{s n} * m_{s n}-V_{a t} * m_{a t}\right) * m_{C l}}{m_{s}} \times 100 \%$

where $V_{s n}$ and $V_{a t}$ is the volume of silver nitrate and thiocyanate solutions, respectively, $m_{s n}$ and $m_{a t}$ are the molarities of silver nitrate and thiocyanate solutions, respectively, $m_{c l}$ is a molar mass of chlorides, while $m_{s}$ is the initial weight of the specimen. ${ }^{43}$ 
a)

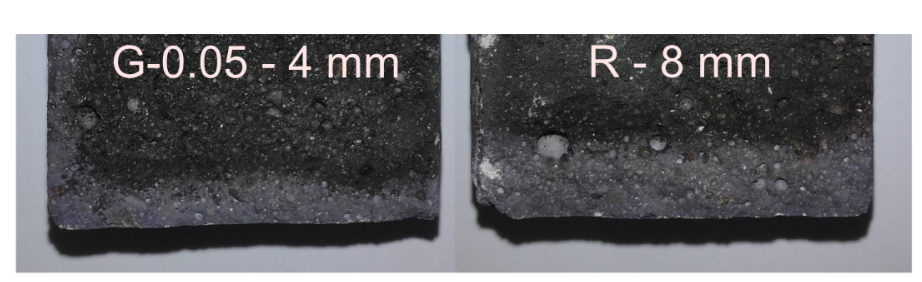

b)

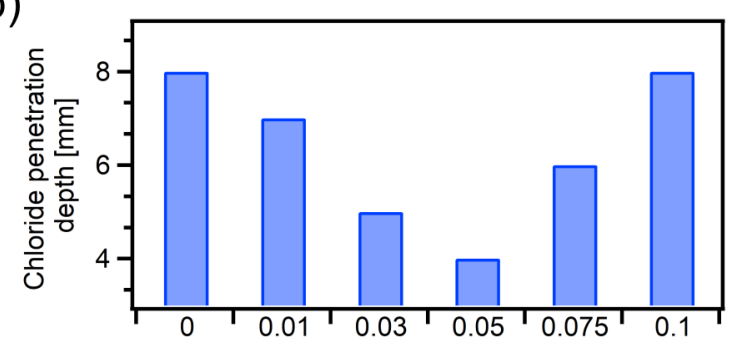

c)

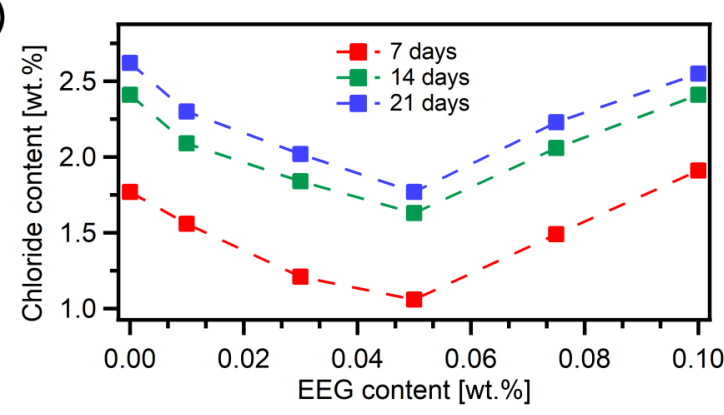

d)

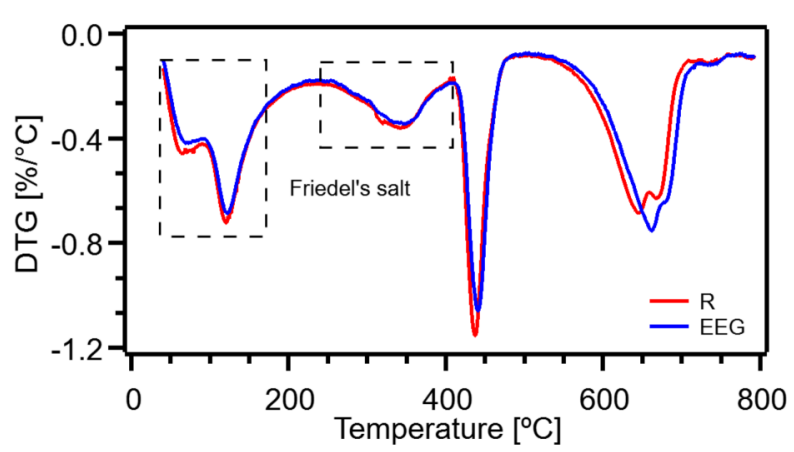

Figure 6. The performance of EEG-cement mortars in chloride environment: (a) R and G-0.05 samples with silvery-white precipitation of $\mathrm{AgCl}$ revealing the chloride penetration depth after 21 days of immersion in $\mathrm{NaCl}$ solution. (b) The chloride penetration depth in all specimens after 21 days of immersion in $\mathrm{NaCl}$ solution. (c) The chloride content in all cement mortars after 7, 14 and 21 days of $\mathrm{NaCl}$ storage. (d) DTG curves for R and G-0.05 samples after 21 days of $\mathrm{NaCl}$ storage.

Figure $6 \mathrm{c}$ shows the chloride content in all cement mortars. We emphasize that the plot reveals a significant correlation with the results of sorption measurements. Indeed, the chloride content in samples with the lowest sorptivity coefficients, i.e., G-0.05 samples, was reduced by $40 \%$ after first 7 days of the exposure to the aggressive $\mathrm{NaCl}$ environment, if related to plain cement mortar. Further comparison of samples stored in $\mathrm{NaCl}$ solution for 14 and 21 days reveals that chloride 
content decreases by $33 \%$ and $32 \%$, respectively, with the introduction of 0.05 wt. $\%$ loading of EEG. Noteworthy, with higher loadings of graphene, the chloride ions amount in cement mortars starts to increase, reaching in G-0.1 composite values comparable to the ones achieved for reference samples. This phenomenon can be explained in terms of the structural characterization of aforementioned composites. As we previously reported, ${ }^{28,29}$ with higher loadings of EEG, in particular $0.1 \mathrm{wt} . \%$ loading, the beneficial effect of graphene incorporation is compromised by low hydration degree and therefore the hindered microstructure of cement paste.

Undoubtedly, the inhibited mobility of chloride ions in composites incorporating EEG can be ascribed, to a great extent, to the markedly reduced sorptivity. However, since the sorptivity coefficients of G-0.05 samples are reduced by $21 \%$ and $25 \%$, while the reduction of chloride content in these specimens is even higher, i.e., by $40 \%$, it is likely that graphene mitigates the chloride-induced corrosion in more ways than just by refining the porosity of cement composites. On the one hand, some authors ${ }^{16}$ attributed the decreased chloride penetration in cement composites to the trapping phenomenon of graphene sheets, acting as extensive barriers restricting the ingress of chloride ions. On the other hand, it should be emphasized that the two main chloride binding mechanisms may occur within cement matrix: physical adsorption and chemical substitution, with two hydrated phases binding the chloride ions - the calcium silicate hydrate (C-S-H) phase and the tricalcium aluminate phase $\left(3 \mathrm{CaO} \cdot \mathrm{Al}_{2} \mathrm{O}_{3}\right)$. As a consequence of the basic reaction with tricalcium aluminate, calcium chloroaluminate $\left(3 \mathrm{CaO} \cdot \mathrm{Al}_{2} \mathrm{O}_{3} \cdot \mathrm{CaCl}_{3} \cdot 10 \mathrm{H}_{2} \mathrm{O}\right)$, commonly known as Friedel's salt, is formed..$^{1,33,44}$

Therefore, since TGA provides direct insight into Friedel's salt content in cement composites, we have opted to extend our studies to additional TG analysis of plain cement mortar and EEGcement mortar after their exposure to $\mathrm{NaCl}$ solution. Basically, the thermal decomposition of 
Friedel's salt occurs at the temperature ranges of $30-180^{\circ} \mathrm{C}$ and $25-400^{\circ} \mathrm{C}$ (Figure $6 \mathrm{~d}$ ) ${ }^{45}$ Although the first peak at $30-180^{\circ} \mathrm{C}$ is associated not only with Friedel's salt, but also with C-S-H phase, ettringite and water evaporation, the calcium chloroaluminate content can be easily estimated on the basis of the second peak at $180-450^{\circ} \mathrm{C}$, since the weight losses at the lower and higher temperature ranges feature with a constant ratio of 4:6. Surprisingly, the content of Friedel's salt turned out to be lower in EEG-based samples only by ca. $3.6 \%$, if compared to plain mortar. These results, coupled with the remarkably reduced chloride content and diffusivity, may suggest that graphene may favor the reaction between chloride ions and tricalcium aluminate, thus leading to the higher formation of Friedel's salt in hardened composites exposed to chloride environment as well as to the higher adsorption of chloride ions within C-S-H phase. Consequently, more chloride ions are adsorbed and therefore the level of free chlorides penetrating cement skeleton is significantly reduced.

\section{CONCLUSION}

In summary, we have demonstrated that the incorporation of EEG in cementitious composites yields significantly enhanced durability. Such improvement is determined by a remarkably decreased penetration of water in the cement mortars leading to a decrease of their initial and secondary sorptivity even by $21 \%$ and $25 \%$, respectively. The investigation conducted in the two common corrosive environments, i.e., chloride and sulfate solutions, revealed the tremendously enhanced resistance of EEG-cement mortars to aggressive agents. In particular, both the chloride penetration depth as well as chloride content were highly reduced in samples incorporating $0.05 \mathrm{wt} . \%$ loading of graphene. Moreover, the presence of EEG showed also to limit the mobility of sulfate ions within cement matrix. Overall, the remarkably enhanced durability of 
EEG-cement composites combined with the simple and efficient manufacturing process may be the key to revolutionize concrete technology. The improved resistance in harmful environments as well as the tremendously enhanced tensile strength of the composites may allow designing lighter and more slender concrete structures. Indeed, since the reduction of cement production due to its negative environmental effects as well as the minimization of high reparation costs represent a major challenge for civil engineering industry, our results are undoubtedly paving the way towards the development of highly durable graphene-based cementitious composites for structural applications.

\section{EXPERIMENTAL SECTION}

Materials. Cement, sand, distilled water and graphene were used in this study to prepare cement mortar. Portland cement CEM I 42.5R was acquired from Gorazdze Cement S.A, while standard sand in accordance with PN-EN 196-144 was purchased from Kwarcmix. The chemical composition of cement is presented in Table S1 in Supporting Information. Graphene was produced by electrochemical exfoliation of graphite foil $(0.5 \mathrm{~mm}$ thick, Alfa Aesar) using a platinum wire (diameter of $0.5 \mathrm{~mm}$, GoodFellow) in an aqueous solution of ammonium sulfate $\left(\mathrm{NH}_{4}\right)_{2} \mathrm{SO}_{4}$ (Sigma-Aldrich). To prepare the corrosion inducing environments, sodium chloride ( $\mathrm{NaCl}$, Fisher Chemicals) and sodium sulfate $\left(\mathrm{Na}_{2} \mathrm{SO}_{4}\right.$, Biomus) were applied. Nitric acid $\mathrm{HNO}_{3}$, silver nitrate $\mathrm{AgNO}_{3}$, ammonium iron(III) sulfate dodecahydrate $\mathrm{NH}_{4} \mathrm{Fe}\left(\mathrm{SO}_{4}\right)_{2} \cdot 12 \mathrm{H}_{2} \mathrm{O}$ and $3,5,5-$ Trimethyl-1-hexanol purchased from Sigma Aldrich as well as 0.1 M ammonium thiocyanate $\mathrm{NH}_{4} \mathrm{SCN}$ solution acquired from Titripur were used to investigate the chloride corrosion resistance of cement composites. 
Electrochemical exfoliated of graphite. Graphene was produced by electrochemical exfoliation of graphite foil..$^{29,47}$ Graphite foil cut into pieces of $2.5 \mathrm{~cm} \times 6 \mathrm{~cm}$ was used as an anode and platinum wire served as a cathode in $0.1 \mathrm{M}$ aqueous solution of $\left(\mathrm{NH}_{4}\right)_{2} \mathrm{SO}_{4}$. The exfoliation of graphite foil was started by a current of $0.4 \mathrm{~A}$ generated by the applied voltage of $15 \mathrm{~V}$ (ISOTECH IPS-603 DC power supply). Finally, graphene was collected after ca. three hours of exfoliation. As produced material was first rinsed several times with water, filtered via polytetrafluoroethylene (PTFE) membranes, dried at $60^{\circ} \mathrm{C}$ for $48 \mathrm{~h}$ and then wiped through a set of sieves with the finest mesh sieve size of $250 \mu \mathrm{m}$. As revealed by our previous characterization, ${ }^{29,30}$ the lateral size of as produced graphene sheets varies between 2 and $5 \mu \mathrm{m}$, with bilayer graphene being a main product (Figure S4). Moreover, the C/O ratio of EEG was estimated at $\sim 3.5$ (Figure S5).

Cement mortar preparation. Reference cement mortar (labelled as R) and five mixtures with graphene (labelled as G) were prepared by mixing cement, sand, water and, if applicable, different loadings of graphene, i.e., $0.01 \mathrm{wt} . \%, 0.03 \mathrm{wt} . \%, 0.05 \mathrm{wt} . \%, 0.075 \mathrm{wt} . \%$ and $0.1 \mathrm{wt} . \%$. The waterto-cement and sand-to-cement ratios were kept constant in all mixes at 0.5 and 3.0, respectively. Graphene was mechanically stirred with cement at low speed (ca. $140 \mathrm{rpm}$ ) using a hand-mixer in order to obtain a homogenous dry mixture. Further mixing procedure was performed according to PN-EN 196-1.46 Water was first mixed with cement at low speed for $30 \mathrm{~s}$. Sand was then steadily added to cement paste during the next $30 \mathrm{~s}$ and the high speed (ca. $285 \mathrm{rpm}$ ) was switched on for additional $30 \mathrm{~s}$. After removing all the mortar adhering the walls of the container, stirring was continued for $60 \mathrm{~s}$ with high speed. Fresh cement mortar was placed in the molds for cubic samples with the dimensions of $40 \times 40 \times 40 \mathrm{~mm}^{3}$. In order to ensure the appropriate compaction of the composites, cement mortar was poured into the molds in two layers, with each layer being 
subjected to vibration on a vibration table for $1 \mathrm{~min}$. All samples were then promptly covered with polyethylene foil to prevent water evaporation. After $24 \mathrm{~h}$, all specimens were demolded and cured in water at $20^{\circ} \mathrm{C}$ for additional 27 days.

Water sorptivity. Liquid capillary sorption tests were conducted on three samples of each cement mortar. At the age of 28 days, specimens were removed from water and oven-dried at $60^{\circ} \mathrm{C}$ to constant mass, i.e., until the mass change was less than $0.1 \%$ in $24 \mathrm{~h}$ (ca. 10 days). The samples were then stored in a sealed container for 15 days to ensure the balanced moisture distribution. Five surfaces of each specimen were covered with epoxy resin to allow water to pass into the specimen only through one surface. After 24 hours, the mass of all samples was recorded as an initial mass and the uncovered surface of the samples were then immersed in water. Cement mortar specimens were stored in a sealed container and the specimens were placed on plastic grid supports allowing to maintain the water level ca. $10 \mathrm{~mm}$ above the uncovered surface of the sample. The specimen mass was measured at specific time intervals after the first contact with water, i.e., at 1, 5, 10 and $30 \mathrm{~min}$, for every 1 -h interval from $1 \mathrm{~h}$ to $6 \mathrm{~h}$ as well as for every 1 -day interval from 1 day to 7 days.

Sulfate attack. In order to evaluate the resistance of cement mortar to the sulfate attack by means of visual assessment and mechanical properties test, three samples of each cement mortar were removed from water and placed in a sealed container with $10 \%$ aqueous $\mathrm{Na}_{2} \mathrm{SO}_{4}$ solution for 56 days. The samples were stored on plastic grid supports allowing to maintain the solution level 10 mm above the upper surface of specimens. $\mathrm{Na}_{2} \mathrm{SO}_{4}$ solution was gently stirred twice a day and replaced once a week. For comparison, other three samples of each cement mortar were further stored in water for additional 56 days. 
After 56 days of the storage in $\mathrm{Na}_{2} \mathrm{SO}_{4}$ solution or water, all samples (six samples for each cement mortar) were visually assessed and subjected to the compression tests. The compressive strength test was conducted according to PN-EN 196-146 using an automatic compression-flexural cement tester (ControlsGroup) at a loading rate of $2.4 \mathrm{kN} / \mathrm{s}$.

In addition, the microstructure of reference cement mortar and cement mortar with 0.05 wt.\% loading of EEG exposed to sulphate environment was investigated using SEM and TGA. To this aim, one sample of each cement mortar was crushed into small pieces of ca. $3 \mathrm{~mm}$ after the standard curing time. The cement mortar pieces were then immediately soaked in $10 \%$ aqueous $\mathrm{Na}_{2} \mathrm{SO}_{4}$ solution or water for 56 days. After 56 days, all the crushed pieces were oven-dried at $60^{\circ} \mathrm{C}$ to constant mass (ca. 5 days).

Two types of SEM images were collected using FEI Dual Beam 235: the images of the external surface of dried pieces of the samples as well as the images of the fracture surface after additional splitting of the pieces. Prior to SEM imaging, the samples were glued to a support with conductive silver paste and sputter-coated with thin layer of gold.

TGA was carried out using Mettler Toledo TGA/DSC 2 sensor. The pieces of crushed cement mortar were, initially, grounded into fine powder and then filtered through a $250 \mu \mathrm{m}$ sieve. Three samples of each cement mortar (of ca. $15 \mathrm{mg}$ ) were placed in alumina crucibles. The specimens were, first, kept isothermally at $30^{\circ} \mathrm{C}$ for $30 \mathrm{~min}$ and then heated up to $800^{\circ} \mathrm{C}$ at a heating rate of $10^{\circ} \mathrm{C} / \mathrm{min}$. The experiments were performed under nitrogen atmosphere.

Chloride penetration. In order to induce the chloride corrosion, three samples of each cement mortar were removed from water and sealed with epoxy resin on five surfaces. After 24 hours, the specimens were placed in a sealed container with $3 \mathrm{M} \mathrm{NaCl}$ aqueous solution for 7, 14 and 21 days. As in the case of water sorptivity measurements, special plastic grid supports were applied 
to ensure the $\mathrm{NaCl}$ solution level ca. $10 \mathrm{~mm}$ above the bottom surface of samples. $\mathrm{NaCl}$ solution was gently stirred twice a day and replaced once a week.

The chloride ion penetration depth was revealed by using silver nitrate solution. Towards this end, one specimen of each mortar was removed from $\mathrm{NaCl}$ solution after 7, 14 and 21 days and split axially. The exposed fracture surface was then sprayed with $0.1 \mathrm{M} \mathrm{AgNO}_{3}$ solution.

In an effort to determine the exact chloride content in cement mortar samples, we used a back titrimetric Volhard method according to BS $1881-124 .{ }^{43}$ The part of the thickness of ca. $8 \mathrm{~mm}$ of the other half of each sample was crushed into fine powder and sieved through the sieve with the mesh of $0.25 \mathrm{~mm}$. The powdered samples were then dried in $105{ }^{\circ} \mathrm{C}$ and $500 \mathrm{mg}$ of each sample was prepared for titration by stirring and heating it for a few minutes with the addition of $50 \mathrm{ml}$ of cold water, $10 \mathrm{ml}$ of nitric acid and $40 \mathrm{ml}$ of hot water. The solution was cooled to room temperature and filtered through a filter paper. At the same time, $0.1 \mathrm{M} \mathrm{AgNO}_{3}$ standard solution was prepared by dissolving $16.989 \mathrm{~g}$ of powdered $\mathrm{AgNO}_{3}$ in water and diluting to 11 . Moreover, iron(III) indicator solution was also prepared: $60 \mathrm{ml}$ of water was added to $50 \mathrm{~g}$ of ammonium ferric sulfate and warmed to dissolve; $10 \mathrm{ml}$ of nitric acid was then added and the solution was cooled. In order to perform the back titration of as prepared samples, $5 \mathrm{ml}$ of $\mathrm{AgNO}_{3}$ solution was added to $10 \mathrm{ml}$ of the sample solution. Noteworthy, since the reaction between ammonium thiocyanate and previously precipitated $\mathrm{AgCl}$ may occur during the titration causing a titration error, $3 \mathrm{ml}$ of 3,5,5-trimethylhexanol was added and the solution was shaken vigorously to coagulate the precipitation and to prevent the aforementioned reaction. An indicator solution was then added and the excess of $\mathrm{Ag}^{+}$ions was titrated using $\mathrm{NH}_{4} \mathrm{SCN}$ solution until the first permanent red color, being an indication of the end of the titration. 
In order to evaluate the Friedel's salt content in reference mortar and mortar with 0.05 wt. $\%$ loading of EEG, we decided to perform TGA measurements. To this end, as in case of sulfate attack, one sample of each cement mortar was splitted into pieces of ca. $3 \mathrm{~mm}$ after the standard curing time. The pieces were then immersed in $3 \mathrm{M}$ aqueous $\mathrm{NaCl}$ solution or water for 21 days prior to oven-drying at $60^{\circ} \mathrm{C}$ for ca. 5 days. TGA measurements were conducted as previously described in paragraph 2.5 .

\section{ASSOCIATED CONTENT}

Supporting Information. The following file is available free of charge.

The chemical composition of CEM I, the results of sorptivity measurements, raw SEM images of EEG-cement mortars, the AFM and XPS analysis of EEG (PDF).

\section{AUTHOR INFORMATION}

\section{Corresponding Authors}

*ciesielski@unistra.fr, samori@unistra.fr

\section{Author Contributions}

The manuscript was written through contributions of all authors. All authors have given approval to the final version of the manuscript.

\section{ACKNOWLEDGMENT}

We acknowledge financial support from the Polish National Science Center (Grant No. 2019/33/NST5/00832), the European Commission through the Graphene Flagship Core 3 project (GA- 881603), as well as the Agence Nationale de la Recherche through the University of 
Strasbourg Institute for Advanced Study (USIAS) and Labex project CSC (ANR-10-LABX-0026 CSC) within the Investissement d'Avenir program (ANR-10-120 IDEX-0002-02), and the International Center for Frontier Research in Chemistry (icFRC).

\section{REFERENCES}

1. Neville, A. M. Properties of Concrete. 5th Edition.; Pearson Education Limited: Harlow, England, 2011.

2. Picker, A.; Nicoleau, L.; Nonat, A.; Labbez, C.; Cölfen, H. Identification of Binding Peptides on Calcium Silicate Hydrate: A Novel View on Cement Additives. Adv. Mater. 2014, 26, 1135-1140.

3. Hobbs, D. W. Concrete Deterioration: Causes, Diagnosis, and Minimising Risk. Int. Mater. Rev. 2001, 46, 117-144.

4. Angst, U. M.; Elsener, B. The Size Effect in Corrosion Greatly Influences the Predicted Life Span of Concrete Infrastructures. Sci. Adv. 2017, 3, 1700751.

5. Du, H.; Pang, S. D. Enhancement of Barrier Properties of Cement Mortar with Graphene Nanoplatelet. Cem. Concr. Res. 2015, 76, 10-19.

6. Miller, S. A.; Moore, F. C. Climate and Health Damages from Global Concrete Production. Nat. Clim. Chang. 2020, 10, 439-443.

7. Cahen, D.; Lubomirsky, I. Energy, the Global Challenge, and Materials. Mater. Today 2008, 11, 16-20. 
8. Monteiro, P. J. M.; Miller, S. A.; Horvath, A. Towards Sustainable Concrete. Nat. Mater. 2017, 16, 698-699.

9. Miller, S. A.; Horvath, A.; Monteiro, P. J. M. Impacts of Booming Concrete Production on Water Resources Worldwide. Nat. Sustain. 2018, 1, 69-76.

10. Li, W.; Dong, B.; Yang, Z.; Xu, J.; Chen, Q.; Li, H.; Xing, F.; Jiang, Z. Recent Advances in Intrinsic Self-Healing Cementitious Materials. Adv. Mater. 2018, 30, 1-9.

11. Lee, J.; Mahendra, S.; Alvarez, P. J. J. Nanomaterials in the Construction Industry: A Review of Their Applications and Environmental Health and Safety Considerations. ACS Nano 2010, 4, 3580-3590.

12. Hanus, M. J.; Harris, A. T. Nanotechnology Innovations for the Construction Industry. Prog. Mater. Sci. 2013, 58, 1056-1102.

13. Shamsaei, E.; de Souza, F. B.; Yao, X.; Benhelal, E.; Akbari, A.; Duan, W. GrapheneBased Nanosheets for Stronger and More Durable Concrete: A Review. Constr. Build. Mater. 2018, 183, 642-660.

14. Yang, H.; Cui, H.; Tang, W.; Li, Z.; Han, N.; Xing, F. A Critical Review on Research Progress of Graphene/Cement Based Composites. Compos. Part A Appl. Sci. Manuf. 2017, $102,273-296$.

15. Li, X.; Lu, Z.; Chuah, S.; Li, W.; Liu, Y.; Duan, W. H.; Li, Z. Effects of Graphene Oxide Aggregates on Hydration Degree, Sorptivity, and Tensile Splitting Strength of Cement Paste. Compos. Part A Appl. Sci. Manuf. 2017, 100, 1-8. 
16. Mohammed, A.; Sanjayan, J. G.; Duan, W. H.; Nazari, A. Incorporating Graphene Oxide in Cement Composites: A Study of Transport Properties. Constr. Build. Mater. 2015, 84, $341-347$.

17. Qureshi, T. S.; Panesar, D. K. Impact of Graphene Oxide and Highly Reduced Graphene Oxide on Cement Based Composites. Constr. Build. Mater. 2019, 206, 71-83.

18. Devi, S. C.; Khan, R. A. Effect of Graphene Oxide on Mechanical and Durability Performance of Concrete. J. Build. Eng. 2020, 27, 101007.

19. Lv, S.; Hu, H.; Zhang, J.; Lei, Y.; Sun, L.; Hou, Y. Structure, Performances, and Formation Mechanism of Cement Composites with Large-Scale Regular Microstructure by Distributing Uniformly Few-Layered Graphene Oxide in Cement Matrix. Struct. Concr. 2019, 20, 471-482.

20. Lv, S.; Zhang, J.; Zhu, L.; Jia, C. Preparation of Cement Composites with Ordered Microstructures via Doping with Graphene Oxide Nanosheets and an Investigation of Their Strength and Durability. Materials 2016, 9, 924.

21. Du, H.; Gao, H. J.; Pang, S. D. Improvement in Concrete Resistance against Water and Chloride Ingress by Adding Graphene Nanoplatelet. Cem. Concr. Res. 2016, 83, 114-123.

22. Mohammed, A.; Sanjayan, J. G.; Nazari, A.; Al-Saadi, N. T. K. The Role of Graphene Oxide in Limited Long-Term Carbonation of Cement-Based Matrix. Constr. Build. Mater. 2018, $168,858-866$. 
23. Jiang, W.; Li, X.; Lv, Y.; Zhou, M.; Liu, Z.; Ren, Z.; Yu, Z. Cement-Based Materials Containing Graphene Oxide and Polyvinyl Alcohol Fiber: Mechanical Properties, Durability, and Microstructure. Nanomaterials 2018, 8, 638.

24. Liu, Q.; Xu, Q.; Yu, Q.; Gao, R.; Tong, T. Experimental Investigation on Mechanical and Piezoresistive Properties of Cementitious Materials Containing Graphene and Graphene Oxide Nanoplatelets. Constr. Build. Mater. 2016, 127, 565-576.

25. Wang, B.; Zhao, R. Effect of Graphene Nano-Sheets on the Chloride Penetration and Microstructure of the Cement Based Composite. Constr. Build. Mater. 2018, 161, 715722.

26. Shang, Y.; Zhang, D.; Yang, C.; Liu, Y.; Liu, Y. Effect of Graphene Oxide on the Rheological Properties of Cement Pastes. Constr. Build. Mater. 2015, 96, 20-28.

27. Hou, D.; Lu, Z.; Li, X.; Ma, H.; Li, Z. Reactive Molecular Dynamics and Experimental Study of Graphene-Cement Composites: Structure, Dynamics and Reinforcement Mechanisms. Carbon 2017, 115, 188-208.

28. Jing, G.; Xu, K.; Feng, H.; Wu, J.; Wang, S.; Li, Q.; Cheng, X.; Ye, Z. The Non-Uniform Spatial Dispersion of Graphene Oxide: A Step Forward to Understand the Inconsistent Properties of Cement Composites. Constr. Build. Mater. 2020, 264, 120729.

29. Krystek, M.; Pakulski, D.; Patroniak, V.; Górski, M.; Szojda, L.; Ciesielski, A.; Samorì, P. High-Performance Graphene-Based Cementitious Composites. Adv. Sci. 2019, 6, 1801195. 
30. Krystek, M. The Assessment of the Applicability of Cementitious Composites Incorporating Electrochemically Exfoliated Graphene in Building Structures; PhD Thesis, Silesian University of Technology: Gliwice, Poland, 2019.

31. Ho, V. D.; Ng, C. T.; Ozbakkaloglu, T.; Goodwin, A.; McGuckin, C.; Karunagaran, R. U.; Losic, D. Influence of Pristine Graphene Particle Sizes on Physicochemical, Microstructural and Mechanical Properties of Portland Cement Mortars. Constr. Build. Mater. 2020, 264, 120188.

32. Ho, V. D.; Ng, C. T.; Coghlan, C. J.; Goodwin, A.; Mc Guckin, C.; Ozbakkaloglu, T.; Losic, D. Electrochemically Produced Graphene with Ultra Large Particles Enhances Mechanical Properties of Portland Cement Mortar. Constr. Build. Mater. 2020, 234, 117403.

33. Kurdowski, W. Chemia Cementu i Betonu; Stowarzyszenie Producentów Cementu, Wydawnictwo Naukowe PWN: Kraków, Warszawa, 2010.

34. Santhanam, M.; Cohen, M. D.; Olek, J. Effects of Gypsum Formation on the Performance of Cement Mortars during External Sulfate Attack. Cem. Concr. Res. 2003, 33, 325-332.

35. Dvořák, K.; Všianský, D.; Gazdič, D.; Fridrichová, M. Thaumasite Formation by Hydration of Sulphosilicate Clinker. Mater. Today Commun. 2020, 25, 101449.

36. Jayalath, A.; San Nicolas, R.; Sofi, M.; Shanks, R.; Ngo, T.; Aye, L.; Mendis, P. Properties of Cementitious Mortar and Concrete Containing Micro-Encapsulated Phase Change Materials. Constr. Build. Mater. 2016, 120, 408-417. 
37. Irshidat, M. R.; Al-Saleh, M. H. Thermal Performance and Fire Resistance of Nanoclay Modified Cementitious Materials. Constr. Build. Mater. 2018, 159, 213-219.

38. Sharma, S.; Kothiyal, N. C. Comparative Effects of Pristine and Ball-Milled Graphene Oxide on Physico-Chemical Characteristics of Cement Mortar Nanocomposites. Constr. Build. Mater. 2016, 115, 256-268.

39. Alarcon-Ruiz, L.; Platret, G.; Massieu, E.; Ehrlacher, A. The Use of Thermal Analysis in Assessing the Effect of Temperature on a Cement Paste. Cem. Concr. Res. 2005, 35, 609613.

40. Mokhtar, M. M.; Abo-El-Enein, S. A.; Hassaan, M. Y.; Morsy, M. S.; Khalil, M. H. Mechanical Performance, Pore Structure and Micro-Structural Characteristics of Graphene Oxide Nano Platelets Reinforced Cement. Constr. Build. Mater. 2017, 138, 333-339.

41. Foley, E. M.; Kim, J. J.; Reda Taha, M. M. Synthesis and Nano-Mechanical Characterization of Calcium-Silicate-Hydrate (C-S-H) made with $1.5 \mathrm{CaO} / \mathrm{SiO} 2$ mixture. Cem. Concr. Res. 2012, 42, 1225-1232.

42. Huang, Q.; Zhu, X.; Zhao, L.; Zhao, M.; Liu, Y.; Zeng, X. Effect of Nanosilica on Sulfate Resistance of Cement Mortar under Partial Immersion. Constr. Build. Mater. 2020, 231, 117180.

43. BS 1881-124: 2015 - Testing Concrete. Methods for Analysis of Hardened Concrete.

44. Florea, M. V. A.; Brouwers, H. J. H. Cement and Concrete Research Chloride Binding Related to Hydration Products Part I : Ordinary Portland Cement. Cem. Concr. Res. 2012, $42(2), 282-290$. 
45. Shi, Z.; Geiker, M. R.; Lothenbach, B.; De Weerdt, K.; Garzón, S. F.; EnemarkRasmussen, K.; Skibsted, J. Friedel's Salt Profiles from Thermogravimetric Analysis and Thermodynamic Modelling of Portland Cement-Based Mortars Exposed to Sodium Chloride Solution. Cem. Concr. Compos. 2017, 78, 73-83.

47. EN 196-1: 2016 - Methods of Testing Cement - Part 1: Determination of Strength.

48. Eredia, M.; Bertolazzi, S.; Leydecker, T.; El Garah, M.; Janica, I.; Melinte, G.; Ersen, O.; Ciesielski, A.; Samorì, P. Morphology and Electronic Properties of Electrochemically Exfoliated Graphene. J. Phys. Chem. Lett. 2017, 8, 3347-3355. 